\title{
MARX, (LOS) MARXISMO(S) Y LA ECOLOGÍA. NOTAS PARA UN ALEGATO ECOSOCIALISTA $^{1}$
}

\author{
HORACIO MACHADO ARÁOZ \\ Universidad Nacional de Catamarca (Argentina)
}

\begin{abstract}
Resumen: ¿Puede el marxismo y la tradición de izquierda en general desconsiderar y/o subestimar la descomunal crisis ecológica (civilizatoria) en la que nos hallamos inmersos? ¿Puede seguir tratándola como un aspecto "secundario" o de "menor relevancia" que la explotación de la fuerza de trabajo? ¿Es la explotación de la naturaleza (apenas) una "segunda contradicción” del capital, que poco y nada tiene que ver con la "lucha de clases"?. Estas preguntas - cuestionamientos constituyen el eje del presente artículo, cuyo objetivo es el de exponer los equívocos teóricos y los extravíos políticos que significó para el marxismo y las experiencias socialistas en general, abrazar el ideal (colonial, burgués y eurocéntrico) del "progreso". Procuramos mostrar que tales extravíos están en las raíces, no sólo del fatal divorcio verificado entre marxismo y ecología, sino también del rotundo fracaso de las experiencias revolucionarias y aspiraciones libertarias del siglo pasado. En contraste, proponemos una revisión de la ontología de Marx, como clave para pensar la radicalidad de su ecologismo y de su horizonte revolucionario. Develar que el capitalismo supone, en el fondo, una contradicción fundamental con la Vida en cuanto tal, con las fuentes de vida y los procesos de vida, incluida la vida en sus formas humanas-sociales, permite superar la falsa dicotomía entre la "emancipación de los trabajadores" vs. la "explotación de la naturaleza" e invita a pensar la revolución como cambio sociometabólico.
\end{abstract}

Palabras clave: Marx; Marxismos; Crisis ecológica; Crisis civilizatoria; Contradicción fundamental.

\footnotetext{
${ }^{1}$ Agradezco los comentarios realizados por el Prof. Carlos Walter Porto Goncalves. Sus observaciones sobre el "espíritu urbano" del capital y las relaciones entre sociedad industrial y sociedad de clases, constituyen para mí, un aporte clave para imaginar (y seguir caminando) hacia horizontes postcoloniales, post-capitalistas; vale decir, descoloniales / ecosocialistas.

${ }^{2}$ Investigador Adjunto CONICET - CITCA (Argentina). Profesor Adjunto Universidad Nacional de Catamarca. Contacto: machadoaterreno@arnet.com.ar.
} 


\section{MARX, MARXISM(S) AND ECOLOGY: NOTES FOR AN ECO-SOCIALIST CLAIM}

Abstract: Can the marxism and the tradition of the left in general ruled out and/or underestimate the huge ecological (civilizatory) crisis in which we are immersed? Can they continue treating it as a "secondary" or "minor" that the exploitation of the work? It is the exploitation of nature (just) a "second contradiction" of the capital, wich has little or nothing to do with the "class struggle"? These questions are the focus of this article, which aims to expose the theoretical mistakes and political deviations that meant for Marxism and the socialist experiences generally embrace the ideal (colonial, bourgeois and Eurocentric) of "progress" . We try to show that such mistakes are in the roots, not only of the fatal divorce verified between Marxism and Ecology, but also the complete failure of the revolutionary experiences and libertarian aspirations of the past century. In contrast, we propose a revision of Marx's ontology, as key to think his radical Ecology and its revolutionary horizon. Revealing that capitalism implies, in the fund, a fundamental contradiction with Life as such, with the sources of life and life processes, including life in its human-social forms, can overcome the false dichotomy between "emancipation workers "vs. "exploitation of nature" and invites us to think of revolution as sociometabolic change.

Keywords: Marx; Marxism; Ecological crisis; Civilizatory crisis; Fundamental contradiction.

\section{Crisis civilizatoria. Desafíos para la humanidad; desafío para (re-inventar) la izquierda}

"La primera premisa de toda la existencia humana y también, por tanto, de toda historia, es que los hombres se hallen, para 'hacer historia', en condiciones de poder vivir” (MARX; ENGELS, La ideología alemana, 1846).

Las primeras décadas del Siglo XXI encuentran a la humanidad sumida en una crucial y definitiva crisis: una crisis ecobiopolítica global que afecta a todas las dimensiones ycondiciones de su existencia. Hace ya casi medio siglo desde su irrupción en la agenda mundial (CUMBRE MUNDIAL SOBRE EL MEDIO HUMANO, Estocolmo, 1972). Sin embargo, muy poco es lo que se ha avanzado en dirección a su superación. Más bien todo lo contrario. En ese trayecto, hemos pasado de su inicial negación hasta su actual estado de naturalización. Su "oficialización" por parte del sistema de Estados y de Naciones Unidas, lejos de contribuir a tratar sus raíces, ha activado nuevos mecanismos de aceleración. Ya ahora, inmersos en el "nuevo paradigma de la economía verde" (FURTADO ET ALT., 2012; ETC, 2012; MORENO, 2013), habitamos un escenario de catástrofes naturalizadas.

Paradójicamente, aún cuando las condiciones elementales de las que depende la vida se han degradado a niveles extremos ${ }^{3}$,y sus impactos pueden contabilizarse en

\footnotetext{
${ }^{3}$ Un pantallazo general sobre la envergadura de la crisis ecológica global puede tomarse de los mismos documentos oficiales como el IPCC (2007), CDB (2006; 2010), FAO (2010). Perspectivas generales sobre la crisis y sus manifestaciones puede consultarse en Hansen (2009); Magdoff y Foster (2010); Elbers (2011); Machado Aráoz (2014);
} 
términos de víctimas humanas ${ }^{4}$, el término "crisis" se limita hoy, prácticamente, al mundo de los valores de cambio. En el imaginario político contemporáneo, "la crisis" se plantea - casi exclusivamente- en términos de "crisis financieras", de "deudas soberanas" y de "balanzas de pagos". Los desequilibrios fiscales y comerciales, el estancamiento del PBI o de indicadores bursátiles, preocupan más que la drástica alteración del clima y el calentamiento global, la pérdida de biodiversidad, la aceleración de la tasa de extinción de especies o la acidificación de los océanos.

Así, en el mundo de los sentidos hegemónicos, lo "ecológico" queda soslayado por lo "económico". La declamada urgencia de los problemas "sociales", se esgrime como justificativo para aceptar la expansión de actividades "económicas", incluso de aquellas claramente destructivas y contaminantes. Pese a que en los últimos cuarenta años la degradación ambiental ha corrido a la par del deterioro socioeconómico de amplias mayorías, pareciera consolidarse un sólido consenso político que acaba subordinando las problemáticas "ecológicas" a la cuestión (esa sí, considerada prioritaria) de "reactivar la economía" y sostener los niveles (los más elevados posibles) de crecimiento. Llegamos al absurdo de, en nombre de "razones humanitarias" (por caso, "luchar contra la pobreza"), justificar la continuación de las múltiples formas contemporáneas de devastación y degradación de la propia Biósfera.

Ahora bien, la gravedad de este panorama no reside tanto en la absoluta ceguera epistémica y política que el sistema hegemónico mundial manifiesta frente a la crucial cuestión ambiental, sino en la incomprensible desidia con que el pensamiento crítico y (la acción política) de izquierda -en sus corrientes dominantes- viene reaccionando frente a la misma. Al fin y al cabo, pocas dudas caben respecto a que es el propio capitalismo el que, en su proceso históricogeográfico de irrupción, expansión y mundialización, nos ha conducido al umbral crítico en el que nos hallamos. Entonces, si respecto de la devastación del mundo de la vida, nada del capitalismo nos debería sorprender (en términos teóricos) y nada cabría esperar (en términos políticos), sí en cambio, nuestras expectativas deberían concentrarse en la tradición crítica y, más específicamente, socialista.

No obstante, el tipo de razonamientos (y de prácticas) que escinde (y antepone) "lo económico" respecto de "lo ecológico" es asumido hoy como propio entre las filas del pensamiento crítico, y aún, pretendidamente marxista. Esto se hizo más

\footnotetext{
${ }^{4}$ Las víctimas por desastres ambientales asociados al cambio climático, categorizados como "refugiados ambientales" por la ONU y la Cruz Roja Internacional han ido creciendo incesantemente en las últimas décadas: de un promedio de 147 millones en los ' 80 , pasaron a 211 millones en los ' 90 y a 255 millones en los primeros nueve años del 2000. Las víctimas fatales por estos eventos también se incrementaron: de 700 mil muertes en la década del '90, a más de un millón 100 mil en el período 2000-2009 (IFRC, 2001; 2009; ONU, 2009). Entre 1988 y 2007, el $76 \%$ de los desastres documentados se vinculan a fenómenos de tipo hidrometeorológico, ocasionando el $85 \%$ del total de víctimas fatales.
} 
pronunciado en el marco de los avatares contemporáneos de las "luchas contra el neoliberalismo"; en especial, en la coyuntura de los (sólo aparentemente contrastantes) procesos sociopolíticos latinoamericanos y europeos de la última década. En tal contexto, la irrupción de los gobiernos progresistas y/o de izquierda en América Latina fue saludada como "superación del neoliberalismo". Sus políticas expansivas fueron esgrimidas como ejemplos a seguir para las "rebeliones contra la austeridad" en Europa, y hasta como vías hacia el "socialismo del siglo XXI".

Tales cambios alimentaron una posición "oficialmente de izquierda" que prioriza el "crecimiento" y que asume que éste es la condición para la "redistribución de la riqueza", que sería la expresión por excelencia de cualquier "política de izquierda". Bajo tales presupuestos, acabaron contraponiendo los objetivos de la "justicia social", la defensa de los "derechos de los trabajadores" frente a los del "cuidado de la Naturaleza". Las luchas contra la "exclusión" en América Latina, y las resistencias a las políticas de "austeridad" en Europa, sirvieron como escenario para que, en nombre de "los intereses de la clase trabajadora", se termine priorizando la "necesidad" de "sostener" los empleos, los salarios, las políticas sociales, antes que ocuparse de los múltiples y gravosos impactos del "crecimiento económico" sobre las bases ecológicas de sustentación de la vida social.

Lamentablemente, pocos toman nota de que sostener el empleo, los salarios, el consumo, etcétera, es sostener el crecimiento, las inversiones, las tasas de ganancia... En fin, el sistema mismo. Así, el énfasis anti-neoliberal ha llevado a ocluir el fondo del problema. Se acabó por priorizar las "políticas de reactivación" frente a los desafios de la transformación revolucionaria. Esto no sólo pauperizó el debate en torno a una serie de oposiciones binarias (Estado versus Mercado; políticas expansivas versus políticas de ajuste; etc.), - todas ellas estrictamente inscriptas dentro de los taxativos límites epistémicos y políticos del capitalismo -, sino que además implicó una profunda devaluación del horizonte político revolucionario. Ahora resulta que el retorno a ciertas variantes de socialdemocracia, de keynesianismo, vino a transformarse en un "horizonte deseable". De tal modo, las cuestiones ambientales y sobre las transiciones postcapitalistas quedaron postergadas sine die.

Así, no deja de resultar irónico que, en nombre de la lucha de clases, se termine abogando por políticas estatales que priorizan el crecimiento económico convencional; o que los "problemas ambientales" se descarten de plano, en nombre de un supuesto "realismo político", centrado en la lucha por el "poder". Nos jugamos la vida, en los desvelos por conseguir un punto más en el "PBI" y/o por "ganar las próximas elecciones".

Ante este panorama, planteado como incitación introductoria, queremos argumentar sobre las inconsistencias teóricas y los extravíos políticos que 
significan para la izquierda en general y para el marxismo, en particular, incurrir hoy en la desconsideración y/o subestimación de la definitiva encrucijada ambiental-civilizatoria en la que nos hallamos inmersos. Por el contrario, nos parece que el ecologismo constituye una dimensión imprescindible a la hora de pensar y afrontar los desafíos de la transformación revolucionaria que, a esta altura de la historia, precisamos realizar.

Insistir en la desconsideración de la cuestión ambiental, sobre todo, subordinarla a las políticas de "crecimiento" (aún con "redistribución de la riqueza"), nos parece un ominoso legado de la vieja izquierda que, lejos de marcar vías para un socialismo del siglo XXI, nos retrotraen a los peores equívocos (burgueses y coloniales) del siglo XIX. Antes que renegar del legado teórico de Marx, el ecologismo ha abierto nuevas pistas de interpretación que vienen a resaltar, a renovar y a radicalizar el potencial crítico-emancipatorio de su pensamiento. Así, es crucial superar el tan equivocado como gravoso divorcio históricamente planteado entre marxismo y ecología.

\section{El divorcio entre marxismo y ecología: orígenes, consecuencias y lecciones de la historia}

"El capitalismo de crecimiento ha muerto. El socialismo de crecimiento, que se le parece como un hermano gemelo, nos refleja la imagen deformada de nuestro pasado, no la de nuestro futuro" (GORZ, Ecología y Libertad, 1977).

Existe, indudablemente, un divorcio histórico entre marxismo y ecología, que persiste de modo aún predominante, en lo que referimos como la "izquierda antineoliberal" de nuestros días. Sin embargo, ésto no obedece tanto a que para Marx las cuestiones ecológicas hayan sido extrañas o siquiera marginales, sino más bien a la fallida experiencia histórica del pensamiento y la práctica política de los socialismos "realmente (in)existentes" del siglo XX; expresión con la cual consideramos tanto a los regímenes del "modelo soviético", como a las distintas variantes socialdemócratas.

En efecto, no se puede desconocer ni minimizar el hecho de que los regímenes políticos instaurados en nombre del socialismo terminaron siendo (además de totalitarios) intrínsecamente anti-ecológicos e insustentables; tan contaminantes, destructivos y despectivos de la Naturaleza, al menos como el propio capitalismo. Tampoco se puede omitir que las expresiones teóricas del marxismo ortodoxo férreamente divulgado y mundializado como "versión oficial" durante el siglo XXse caracterizaron por una profunda ceguera respecto a la cuestión ecológica (así como a otras dimensiones igualmente importantes de la dominación y la alienación capitalista, tales como, las problemáticas del sexismo, el patriarcado, el 
colonialismo y el racismo, los desafíos de la diversidad cultural y la democratización radical de la vida social).

Salvo honrosas excepciones, ese marxismo abrazó por completo la fe ciega en el progreso, esto es, el credo cuasi-religioso -propiamente moderno-colonialcapitalista-, delevolucionismo, el cientificismo, la omnipotencia tecnológica y el crecimiento infinito como horizonte universal y deseable de la historia. Más allá de sus drásticas consecuencias el mundo entero, esto significó para el marxismo y la tradición socialista en general, un lapidario equívoco epistémico e históricopolítico que acabó no sólo aplastando -bajo los escombros de sus propias edificaciones- las experiencias de luchas anti-capitalistas nacidas bajo su inspiración, sino también embargando y atrofiando su potencial críticoemancipatorio.

Vistos retrospectivamente, los socialismos del siglo XX terminaron resultando, apenas, una variante colectivista del mismo proyecto civilizatorio del capitalismo. Como quedara patentado en la fulminante definición de Lenin ("el socialismo es igual a soviets más electricidad"), dichos "socialismos" procuraron superar los estragos del capitalismo, pero manteniendo los que se consideraron sus "avances y beneficios". En el plano teórico, esto significó abrir una versión extremadamente reduccionista de la crítica de Marx; y en el plano histórico-político, condujo a seguir la misma ruta extraviada del capitalismo -ya largamente iniciada por él-, pretendiendo el absurdo de "alcanzarlo" y "superarlo" por la vía de su emulación.

De tal modo, lejos de dar lugar a la constitución de modelos de vida y de organización social radicalmente alternativos, las experiencias socialistas del siglo pasado terminaron siguiendo la misma senda histórica moldeada por el capitalismo. Salvo por la cláusula de la colectivización (en realidad, estatalización) de la propiedad sobre los medios de producción, compartieron casi por completo el imaginario civilizatorio de la modernidad colonial-capitalista. La idea de cambio revolucionario se restringió, así, a la apropiación, control y/o redistribución del excedente, ya por la vía directa del control estatal sobre los medios de producción, o ya por la vía reformista de la creciente mediación, también estatal, en la asignación social de las capacidades de consumo. Pero en todo caso se mantuvo incuestionado tanto el régimen de relaciones sociales en base a las cuales se produce dicho excedente, cuanto la idea misma del excedente como la expresión suprema de valor y medida de realización social.

Así, entre el "bloque soviético" y el "bloque capitalista", el antagonismo se dio a nivel geopolítico, no de modelos civilizatorios. Las diferencias entre "comunismo", "socialdemocracia" y "capitalismo" fueron, apenas, institucionales, no de concepción y proyectos históricos de vida. Tales modelos constituyeron sólo variantes de un mismo patrón de poder mundial (QUIJANO, 2000).

$\mathrm{Y}$, como a esta altura de la historia resulta evidente, el problema del capitalismo no es sólo el de la propiedad privada de los medios de producción, sino de la 
totalidad del modelo societal-civilizatorio que se erige sobre su base. La sustitución de una clase de propietarios individuales y un régimen oligopólico de corporaciones, por una clase de funcionarios al comando de un régimen monopólico de estado, no suprimió ni las desigualdades sociales, ni la explotación de la fuerza de trabajo; ni el poder gerencial burocrático sobre los cuerpos.

$\mathrm{Al}$ dejar intactos sus presupuestos fundamentales, las vías de la vieja izquierda de "superación" del capitalismo, terminaron compartiendo la misma ceguera civilizatoria y reproduciendo - aunque bajo otras modalidades - los mismos problemas de insustentabilidad radical. Dejando de lado la compleja diversidad de dimensiones sobre los límites y extravíos políticos en general de estas experiencias, acá nos interesa simplemente marcar cuatro cuestiones o fallas civilizatorias, que nos parecen claves para re-pensar y re-crear el socialismo para el siglo XXI.

\section{La crucial cuestión de los límites}

La cuestión de los límites fue la primera y más elemental manifestación de la crisis de sustentabilidad del patrón civilizatorio moderno-colonial-capitalista. Identificada de modo directo en el título del Primer Informe Meadows (Los límites del crecimiento, 1972), allí saltó a la vista la inverosimilitud de un "sistema económico" estructurado en base a una dinámica de crecimiento infinito, dentro de un mundo con taxativos límites geo-físicos y biológicos.

En la raíz del problema situamos el proceso histórico de separación y abstracción de la economía política (epistémica y prácticamente concentrada en el universo de las mercancías/dinero) respecto de los procesos vitales-materiales en general ${ }^{5}$, fenómeno que se materializa mediante la subordinación del valor de uso a la generación y acumulación del valor de cambio. Como lo advirtiera Marx, el capital se configura sobre la base de la primacía absoluta del valor de cambio; ello da lugar a una economía imaginaria que no sólo no reconoce ni admite límites a su expansión, sino que por el contrario, hace del crecimiento infinito su presupuesto básico y requisito funcional ${ }^{6}$.Esta problemática tiene, por lo menos, dos dimensiones: una biofísica y otra biopolítica.

\footnotetext{
${ }^{5}$ En Naredo (2006) puede hallarse un estudio del desarrollo histórico de las distintas escuelas de pensamiento de la economía política moderna, donde se pone énfasis en este creciente desentendimiento que la disciplina económica respecto del mundo de la naturaleza en general y de los procesos materiales en particular.

${ }^{6} \mathrm{Al}$ respecto, Hermann Daly plantea: "La desviación del enfoque del valor de uso al valor de cambio que acontece con la circulación mercantil D-M-D' es crucial. La acumulación de bienes y valores de uso es autolimitante. (...) Pero el valor de cambio de los bienes en general, abstraído en forma de dinero, se torna el centro de la acumulación. No hay nada que limite el valor de cambio abstracto que se puede tener. (...) De hecho, el valor de cambio abstracto crece por sí mismo, dando intereses, y luego intereses sobre los intereses. Marx, y Aristóteles antes que él, señalaron el peligro de este
} 
En términos biofísicos, el problema de los límites no es nuevo en la economía.Su tratamiento se remonta, por lo menos, al siglo XIX, en el que autores de diversas procedencias - desde Fourier a Darwin, Huxley, Moebbius, Jevons, Liebig, Geddes, Reclus, entre otros- abordaron la cuestión de los efectos devastadores que sobre los ecosistemas tienen los nuevos principios y fines mercantiles de las actividades económicas ${ }^{7}$. Sin embargo, los estudios decisivos en el campo de la crítica a los planteos del "crecimiento infinito" se dan a partir de los desarrollos de la economía ecológica, cuyo enfoque justamente se centra en los flujos energéticos y no en los monetarios. Desde las intuiciones pioneras de Podolinsky, esta perspectiva daría un vuelco definitivo, con la aplicación del segundo principio de la termodinámica a los procesos económicos, de la mano de los trabajos de Nicholas Georgescu-Roegen (GEORGESCU-ROEGEN, 1977; PASSET, 1996; LEFF, 1994; MARTINEZ-ALIER, 2004; VIVIEN, 2011).

En términos biopolíticos, cabe recordar que la noción de "límite" refiere a lo político en sî́. En este sentido, las implicaciones del "crecimiento (supuesto) infinito" sobre la trama cuerpos/ dominación, han sido inicialmente señaladas por Marx en su análisis sobre el fetichismo y los procesos de fetichización, luego retomadas en el pensamiento de Gramsci, Luckács, Benjamin, Marcuse y Debord, entre otros. Esto hace parte de la dimensión más compleja de la dominación capitalista, ya que remite a los efectos que el proceso de realización del capital tiene sobre la configuración histórica de la materialidad de lo humano, aspecto sobre el que volveremos más adelante. Acá nos limitamos a señalar que la fascinación del capital reside en buena medida en la ilusión fantasmagórica de ofrecer un "mundo infinito", donde siempre es posible "más" y donde nunca nada resulta "suficiente". Esto se transforma en un vector clave de la estructuración de las subjetividades y de las sociabilidades del sistema. Y, por otro lado, está también

fetichismo del dinero. (...) En nuestra época, este proceso histórico de abstraerse cada vez más del valor de uso ha sido llevado quizás al límite en la así llamada "economía de papel", que puede ser simbolizada como D-D', la conversión directa de dinero en más dinero, sin referencia a los bienes ni siquiera como un paso intermedio". (DALY, 2013, p. 53. Resaltado nuestro).

${ }^{7}$ Sólo a modo ilustrativo cabría mencionar el destacado caso de Justus von Liebig, cuyos estudios sobre la degradación de la fertilidad del suelo provocada por la transformación capitalista de la agricultura en Inglaterra y Alemania fueron claves para los análisis de Marx sobre el metabolismo social del capital, al que nos referiremos más adelante. También resulta muy interesante mencionar la opinión del biólogo escocés Patrick Geddes que en 1884 señalaba que la economía - siguiendo la clasificación de Comte- todavía "estaba en su fase metafísica, toda que se trataba de una ciencia abstracta y de pura lógica, centrada en cuestiones de valor y precio de equilibrio, ignorando totalmente sus fundamentos materiales y energéticos" (cit. por VIVIEN, 2011, p. 64).

${ }^{8}$ Según el geógrafo brasileño Carlos Walter Porto Goncalves, "política es el arte de definir los límites" (PORTO-GONCALVES, 2004, p. 33). Más aún, la noción de límite expresa y hace a la especificidad de la condición humana, en tanto su voluntad no está determinada por límites naturalmente impuestos. Por el contrario, el proceso de "delimitación" (es decir, la tarea de definir conceptual y prácticamente cuáles son los límites en todo sentido para lo humano) expresan la tarea y el desafío ético y político por excelencia que define lo humano. 
en los principios generativos de la violencia; es decir, da cuenta de la particularidad histórica que la violencia presenta bajo el capitalismo, donde la guerra se convierte en la forma normal de establecer los límites.

Ahora bien, pese a que la cuestión del "crecimiento infinito" constituye un supuesto manifiestamente contradictorio con el materialismo, y pese a que se trata de una dimensión clave de la dinámica de dominación del capital, las experiencias socialistas del siglo XX y la izquierda en general apegada al "marxismo científico", abrazaron casi incondicionalmente la ideología del crecimiento perpetuo. Desde Lenin y su propuesta de la NEP a principios del siglo pasado, hasta los actuales exponentes del "socialismo del siglo XXI" en América Latina pasando por las políticas de la revolución china, la cubana y las socialdemócratas en general-, los gobiernos dichos "socialistas" han defendido sistemáticamente las políticas de crecimiento, como una "necesidad histórica"; una condición, si no suficiente, sí indispensable para cualquier "transición al socialismo".

Esto nos sitúa, en términos lógicos, ante un oxímoron: intensificar el crecimiento (del capitalismo) para superar el capitalismo. Y, en términos políticos, ante un punto límite y un crucial desafío histórico para el pensamiento crítico: más allá de los efectos de verdad de la ideología del crecimiento infinito, los límites como atributo de la materialidad del mundo- existen insoslayablemente; de modo tal que sin propuestas teóricas, políticas e institucionales que piensen y construyan los modos de definir los límites de la producción material, no hay forma de salir de la economía de guerra del capital.

\section{La cuestión de la explotación/alienación del trabajo/naturaleza}

Otro de los reduccionismos fatales de las experiencias socialistas del siglo pasado es el relativo al abordaje de la explotación de la fuerza de trabajo, generalmente considerada en forma aislada de la dinámica sociometabólica del capital y de los regímenes de (producción de) naturaleza y de subjetividad inherentes al proceso de acumulación-como-fin-en-sí-mismo. Sobre la misma base antropocéntrica de la filosofía liberal, el marxismo ortodoxo abordó la contradicción capital/trabajo no sólo como "fundamental" sino, prácticamente como contradicción exclusiva. Entre otras implicaciones, esto provocó una profunda ceguera tanto respecto a la cuestión ambiental cuanto sobre las complejas formas de la alienación.

Sobre lo ambiental, es evidente que para los socialismos del siglo pasado la "explotación de la naturaleza" fue una cuestión independiente y en todo caso secundaria de la "explotación del trabajo", primando una concepción ya sacrificial, ya etapista sobre los problemas ambientales (es decir, visiones donde la degradación ecológica se justifica, si fuera un medio necesario -transitorio o no- 
para "alivianar" o "superar" la explotación de los trabajadores). Esta posición nace de una falaz separación entre sociedad y naturaleza que -como veremos- no encuentra sustento en el pensamiento de Marx.

Tal como fuera explicitado en su análisis sobre "La llamada acumulación originaria", el capitalismo nace como una fuerza violenta de mercantilización que avanza sobre la tierra y sobre los cuerpos-de-productores, así expropiados de sus medios de producción/vida.El capital -como condición para su propia existenciacrea un nuevo régimen de naturaleza, basado en la objetualización - cientifización - mercantilización de los así llamados "recursos naturales" para ser crecientemente subsumidos como objetos y medios de trabajo del proceso de producción y acumulación de plusvalor. Así, es la instauración de ese régimen de naturalezamercancía, la precondición histórica y requisito económico-político para la mercantilización de los cuerpos-de-productores. Dicho de otro modo, es la expropiación, mercantilización y explotación de la tierra la que crea el régimen salarial. Por tanto, no se trata de dos procesos distintos, sino de dos aspectos de un mismo proceso histórico-político.

La imbricación intrínseca existente entre apropiación/explotación de la tierra (naturaleza exterior) y apropiación/explotación de la fuerza de trabajo (naturaleza interior), permite develar también cómo el capital precisa crear no sólo un régimen de naturaleza sino también un régimen de subjetividad adecuado al imperativo de la acumulación. Y esto se refiere directamente a la cuestión de la alienación, que involucra -claro- el proceso de deshumanización de los trabajadores mediante su sometimiento a los engranajes de las fuerzas productivas del capital durante la fase de la producción, pero también, y sobre todo, el proceso de internalización de la dominación / mercantilización del deseo que se realiza en la fase del consumo (MARCUSE, 1964; BAUDRILLARD, 2007; BAUMAN, 1998; 2007; BOLTANSKI; CHIAPELLO, 2002; GUATTARI; ROLNIK, 2005; SCRIBANO, 2013).

Esto último en particular, ha sido significativamente omitido y/o desconsiderado en las experiencias socialistas del siglo pasado. Sobre todo, en cuanto las luchas contra la "explotación del trabajo" se centraron, no en la superación de la condición salarial, sino en la reivindicación de "derechos laborales y sociales" y el "mejoramiento del poder adquisitivo del salario", tales "conquistas" terminaron resultando, no anti-sistémicas, sino profundamente funcionales a la dinámica sociometabólica del capital. Paradójicamente, cada paso adelante dado en esa lucha, significó, un correlativo y proporcional avance en la consolidación, intensificación y profundización del capitalismo; no su debilitamiento, no el agrietamiento de sus bases materiales y simbólicas de legitimación, sino todo lo contrario, hasta llegar al punto (neoliberal) de su naturalización como "único mundo posible". 
En términos generales, esta dinámica alimentó una desenfrenada carrera por la producción y por el consumo; lo que puede ser considerado -hasta ahora- como uno de los hechos más ruinoso para la historia de la humanidad, en términos ecológicos y políticos. Si en lo ecológico implicó llegar al extremo de ultrapasar los límites de sustentabilidad de la biósfera, en términos políticos significó el completo extravío del horizonte revolucionario y el anestesiamiento de las rebeliones libertarias e igualitarias. La escalada productivista/consumista -que se gatilló tanto en nombre del capitalismo, como de la lucha contra el capitalismo-, marcó en realidad, el pasaje de un capitalismo centrado en la producción, en la intensificación de los ritmos del trabajo productivo y los aumentos de productividad, a otro donde el núcleo de las preocupaciones pasa a ser el de sostener y alentar una dinámica de demanda creciente y consumo masivo?.

La cuestión epistémica de fondo de este fallido histórico tiene que ver con la naturalización de los conceptos de "riqueza", de "valor", y de "trabajo" que el capitalismo inaugura e instituye, y cuya tarea de desnaturalización fuera el núcleo de la crítica de Marx. Sobre la base de esas naturalizaciones, opera el dispositivo ideológico de "lucha contra pobreza" y los argumentos pseudo-humanitarios de justificación de la "necesidad de aumentar la producción" como condición para "superar la explotación"/ "cubrir las necesidades insatisfechas" de los "excluidos", etc. Esta perspectiva pierde de vista que la lógica de la acumulación no se realiza sólo a través de un sistema de producción de mercancías, sino que también involucra -a través de aquellas- un sistema de producción de necesidades. Y el capitalismo, sobre todo en los últimos 70 años, ha funcionado como una gran fábrica biopolítica de producción de necesidades. Esas "necesidades" son necesarias, no para las personas, sino para el sistema. Dicho de otro modo, las "necesidades" - en este marco- vienen a designar el nombre de las cadenas que nos mantienen sujetos al sistema, que nos hacen ser sujetos-del-sistema.

Así, con las transformaciones aludidas en la segunda mitad del siglo pasado, el capital inaugura una nueva fase y un nuevo horizonte de apropiación y disposición de las energías sociales, marcadas por la intensificación e internalización de la alienación. Mientras que bajo la lógica del capitalismo pre-keynesiano, la dominación del capital se ejercía predominantemente como un poder exterior, donde la disciplina fabril funciona como un mecanismo de control y manipulación que se apropia y usufructúa de las energías corporales desde afuera, bajo la dinámica consumista del keynesianismo y el postkeynesianismo, la dominación opera desde la interioridad misma de los cuerpos, moldeando las subjetividades, sus formas de ver y sentir el mundo, a partir de la eficacia regimental/libidinalde la

\footnotetext{
${ }^{9}$ No cabe pasar por alto que éste ha sido un tema central de la sociología y la economía crítica de la época de posguerra, donde destacamos los trabajos de Henry Lefebvre, David Riesman, Harry Braverman, Paul Baran y Paul Szweezy, Vance Packard, Charles Wright Mills, Guy Debord, Jean Baudrillard, entre otros.
} 
forma mercancía. Aquí ya, el capital se apropia de las energías corporales, psíquicas y emocionales a partir de la colonización del deseo y la sobredeterminación de la estructura de necesidades/sensibilidades que nos "hacen sujetos" 10 .

Tomar nota de estos mecanismos y procesos, buscar alternativas y estrategias para romper con estas complejas formas de la dominación/alienación, es un desafío clave e insoslayable para pensar la re-creación del socialismo en el siglo XXI.

La cuestión (del fetichismo) de la tecnología, el régimen tecno-burocrático y la expropiación de las condiciones materiales de la autonomía

Un tercer problema/límite intrínseco al mismo patrón civilizatorio del capital que fue omitido por las experiencias socialistas del siglo pasado es la cuestión de las implicaciones no sólo ambientales, sino también culturales y políticas del patrón tecnológico y organizacional resultante del imperio monolítico de la racionalidad instrumental.

El marxismo tradicional, construido en base a la negación y al rechazo del Marx "romántico" (LÖWY, 1991), asumió la fe iluminista en el "progreso de la ciencia" como un instrumento aproblemático para la liberación del ser humano (LANDER, 1994; O’CONNOR, 2001). Hasta bien entrado el siglo XX:

la mayoría de los marxistas consideraban aún las fuerzas productivas - en particular las ciencias y la técnica - como ideológicamente neutras, y su desarrollo, como intrínsecamente positivo. Con frecuencia sostenían que la maduración del capitalismo producía una base material sobre la cual podría edificarse el socialismo mucho más fácilmente, al tener un elevado desarrollo de las fuerzas productivas del capitalismo. (GORZ, 2008, p. 65).

Esto constituyó uno de los puntos ciegos más gravosos de dichas experiencias y, de modo increíble, sigue operando todavía como un pesado lastre en ciertas expresiones contemporáneas "de izquierda".

No obstante, las críticas a esta concepción prometeica del desarrollo tecnológico surgieron tempranamente y fueron una constante dentro del pensamiento marxista, por caso, desde William Morris, en el siglo XIX, hasta Barry Commoner en el presente. La presunción de "neutralidad" política de la ciencia y la tecnología

\footnotetext{
${ }^{10}$ Tomamos como base de estas consideraciones los desarrollos fundamentales de la sociología de los cuerpos/emociones desde una perspectiva marxista realizados por Adrián Scribano. Véase (SCRIBANO, 2009; 2010; 2012; 2013a; 2013b; SCRIBANO; DE SENNA, 2014).
} 
constituye un postulado que no resiste el menor análisis. En este campo, las críticas de la Escuela de Frankfurt resultan emblemáticas, de una vigencia indiscutible. Las mismas invitan a preguntarse sobre la especificidad histórico-política de la tecnología emergente bajo el capitalismo: ¿cuál es la función que cumple?, ¿cuáles son los intereses cognoscitivos y prácticos que dirigen y regulan tanto el sistema de producción de conocimientos cuanto el proceso de innovación tecnológica?; ¿hacia qué fines está dirigido? (HABERMAS, 1968; 1982).

Especificando tales cuestiones, James O'Connor plantea que, dentro del capitalismo, la tecnología cumple - aparte de funciones sociales, políticas e ideológicas- tres principales funciones económicas: a) "maximizar (...) la explotación del trabajo y las tasas de utilidad y acumulación capitalista"; b) "reducir los costos de extracción de materias primas y combustibles y/o aumentar la eficiencia de uso de aquéllos"; y c) "desarrollar nuevos bienes de consumo y expandir los mercados de consumo" (O'CONNOR, 2001, p. 240-241).

En correspondencia con lo expresado en el ítem anterior, el patrón tecnológico que emerge de la subordinación de los procesos vitales al imperativo de la acumulación, tiene consecuencias tanto ambientales y ecosistémicas, como antropológicas, políticas y culturales. Respecto de las primeras, ya hemos señalado cómo el capital avanza en su dinámica de acumulación privatizando los bienes de la naturaleza, explotando los "recursos" de libre disponibilidad, sin límites hasta que éstos se convierten en un "costo" de producción (O'CONNOR, 2001), y aún así, aprovechando ese agotamiento/contaminación como una fuerza más de mercantilización de la naturaleza (O'CONNOR, 1994); haciendo de la escasez socialmente producida por el proceso de sobre-explotación, un nueva fuente de ganancia (FOSTER, 2007; 2010).

Respecto de las funciones/implicaciones ideológico-políticas y socioculturales de la tecnología, como se dijo, tempranamente los trabajos de Adorno, Horkheimmer, Benjamin y Marcuse alertaron sobre los extravíos de apostar a la emancipación social apelando al desarrollo de una misma racionalidad, bajo la cual, "lo que se impone es una determinada forma de oculto dominio político" (HABERMAS, 1968, p. 54). A través del "desarrollo de las fuerzas productivas" lo que se produce es "la intensificación del sometimiento de los individuos al inmenso aparato de producción y distribución" (MARCUSE, 1957. cit. por HABERMAS, 1968, p. 54).

El control y el dominio sobre la naturaleza que hace posible el aparato científico-tecnológico emergente como brazo operativo del capital se extiende también inevitablemente en formas organizacionales, de división y control social del trabajo que, lejos de crear condiciones de autonomía, implican la centralización, jerarquización y verticalización del poder. Esta tendencia totalitaria es señalada por Marcuse, como un rasgo intrínseco a la ciencia positiva que está en la base de los modelos racional-burocráticos, tanto en su versión empresarial- 
corporativa, como en su variante estadocéntrica. En "El hombre unidimensional" planteaba que

el método científico, que conducía a una dominación cada vez más eficiente de la naturaleza, proporcionó después también tanto los conceptos puros como los instrumentos para una dominación cada vez más efectiva del hombre sobre el hombre a través de la dominación de la naturaleza... Hoy la dominación se perpetúa y amplía no sólo por medio de la tecnología, sino como tecnología; y ésta proporciona la gran legitimación a un poder político expansivo que engulle todos los ámbitos de la cultura.

Y continúa:

en este universo la tecnología proporciona también la gran racionalización de la falta de libertad del hombre y demuestra la imposibilidad técnica de la realización de la autonomía, de la capacidad de decisión sobre la propia vida. Pues esta ausencia de libertad no aparece ni como irracional, ni como política, sino más bien, como sometimiento a un aparato técnico que hace la vida más cómoda y eleva la productividad del trabajo. La racionalidad tecnológica, respalda de ese modo la legalidad del dominio; y el horizonte instrumentalista de la razón se abre a una sociedad totalitaria de base racional (MARCUSE, 1964, p. 177-178).

En definitiva, tanto o más graves que los impactos de contaminación y depredación que la tecnósfera gestada al servicio de la acumulación tiene sobre la biósfera, son los problemas sociopolíticos provocados en términos de configuración de modelos organizacionales y gestión autocráticos, jerárquicos y totalitarios. "En la experiencia soviética", al decir de Lander, "estos mismos modelos tecnológicos centralizados, no democráticos, usurpadores del conocimiento de los trabajadores, depredador de la naturaleza (...) fueron llevados a extremos desconocidos en las propias sociedades capitalistas centrales" (LANDER, 2007, p. 228).

\section{El régimen socioterritorial urbanocéntrico.}

Ese mismo poder tecnocrático no sólo se expande sobre el ámbito de la institucionalidad y las sociabilidades, sino que también se traduce y se materializa en un específico régimen socioterritorial, igualmente configurado desde la lógica 
del dominio y el control, la expropiación de las condiciones materiales de la autonomía. En este punto, tal como fuera también señalado en sus orígenes por Marx, el capitalismo es inseparable del proceso de urbanización, así constituida como sinónimo de "civilización" y de "progreso", en oposición directa a lo campesino y lo rural como encarnación del atraso y lo in-culto (lo cual en realidad, es una contradicción/negación de su etimología). La conformación de la ciudad moderna, la concentración masiva de los cuerpos expropiados de sus condiciones vitales, fue una condición histórica de posibilidad de la irrupción del régimen de relaciones sociales - de producción y destrucción- del capital. Al respecto, es claro que:

a una ideología de clase, a una forma de poder y de propiedad, a un tipo de tecnología y de fuentes energéticas, tiende a corresponder un tipo de urbanización, esto es, un modo de localización del hábitat, (...) de equipamientos de infraestructura, un modo de apropiación y de implantación en el espacio de las actividades de producción" (RODRIGUES, 1975, p. 11).

En este sentido, no es posible omitir que la ciudad nace como dispositivo geoespacial de control y disposición de los cuerpos-de-trabajadores; es, como tal, una forma alienada del territorio. La ciudad expresa una territorialidad heteronómica por excelencia, puesto que se edifica sobre la imposibilidad de la autonomía material y la autosustentación; de la misma manera que la división social entre trabajo manual y trabajo intelectual constituye un dispositivo clave de la expropiación de las capacidades de autogestión y desarrollo de los trabajadores en mano de "empleadores" y de "gerentes", la partición de la sociedad entre el campo y la ciudad funciona como mecanismo de producción social de las dependencias vitales (esto es, la dependencia alimentaria, hídrica y energética) fundamentales de las poblaciones regimentadas en los espacios urbanos.

En definitiva, el "optimismo histórico" del marxismo científico (GOULDNER, 1982), implicó el absurdo de buscar la "superación del capitalismo" apostando al desenvolvimiento de las mismas fuerzas científico-tecnológicas, socioterritoriales, organizacionales y motivacionales que están en la propia base de su dinámica de acumulación. La fe común en el "mundo del progreso" licuó las diferencias epistémicas y políticas entre capitalismo y socialismo (del siglo XX). La miopía epistémico-política de esta vía significó una drástica limitación de la crítica y de la praxis revolucionaria, que dejó fuera de su alcance, la consideración sobre las condiciones y las implicaciones ecobiopolíticas del capital como régimen de relaciones sociales y como modelo civilizatorio, pretendido universal.

A esta altura de los acontecimientos, no nos queda más que sacar las lecciones de la historia, para hacer de ellas, nuevas fuentes de la imaginación revolucionaria. 
Para nosotros, el punto de partida, es volver a indagar críticamente en las raíces de la alienación humana y de la alienación del mundo (ARENDT, 2003); es decir, volver a revisar el ecologismo de Marx.

\section{El ecologismo de Marx (o las raíces de la alienación humana en el capitalismo)}

"Lo que necesita explicación, o es resultado de un proceso histórico, no es la unidad del hombre viviente y activo, con las condiciones inorgánicas, naturales de su metabolismo con la naturaleza, y por lo tanto, su apropiación de la naturaleza, sino la separación entre estas

condiciones inorgánicas de la existencia humana y esta existencia activa, una separación que por primera vez es puesta plenamente en la relación entre trabajo asalariado y capital"

(MARX, Grundrisse, 1857).

A contracorriente de las interpretaciones predominantes, cabe afirmar que Marx de ninguna manera desconoció (ni subestimó) los (irresolubles) problemas socioambientales inherentes al desarrollo histórico-geográfico del capitalismo. Tal como se puede constatar en general en los desarrollos del ecomarxismo, el pensamiento de Marx provee elementos que resultan fundamentales para comprender en profundidad la naturaleza y etiología de la crisis ecológica bajo el capitalismo, así como imprescindibles a la hora de proyectar alternativas políticas (realistas y emancipatorias) frente a la crucial -y definitiva- crisis civilizatoria que afrontamos en el presente siglo (LÖWY, 2011; O'CONNOR, 2001; FOSTER, 2000; MAGDOFF; FOSTER, 2010).

No se trata de intentar, subrepticiamente, "reverdecer" a Marx. A nuestro entender, el "ecologismo" de Marx no hace referencia a elementos desconocidos, secundarios o marginales de su pensamiento, ni se restringe superficialmente a un agregado (más o menos extenso) de citas esporádicas a lo largo de su vasta obra. Por el contrario, la cuestión ecológica en Marx es una dimensión intrínseca, central e inseparable de su crítica de la economía política.

Mejor dicho, la crítica de la economía política que Marx inaugura sitúa, en la raíz de la dominación capitalista, la forma (inapropiada) de entender, relacionarse (y producir) la naturaleza que el capital instaura como condición para su propia existencia. Para Marx, es el propio régimen de realidad que instituye el capital -contrario a la materialidad del mundo; por tanto erigido en contradicción de las condiciones fundamentales de la vida- lo que está tanto en las raíces de la alienación, humana en particular, y del mundo- de-la-vida en general.

Así, lo que a nuestro entender constituye la particularidad - y la radicalidad de la ecología de Marx es que ésta se basa, en última instancia, en su ontología materialista histórico-dialéctica (SCHMIDT, 1976). En efecto, al pensar los fundamentos de la realidad, en lugar de la conciencia y/o de los objetos, Marx parte del cuerpo. Para Marx "(L)la primera premisa de toda la historia humana es 
la existencia de individuos humanos vivos. El primer hecho a constatar es, por tanto, la organización corpórea de esos individuos y la relación por eso existente con el resto de la naturaleza" (MARX; ENGELS, 1974, p. 19). Se trata de una premisa fundamental sobre la que se edifica todo el pensamiento filosófico, antropológico y político de Marx; tiene importantísimas implicaciones, de las cuales acá, nos interesa destacar tres.

En primer lugar, partir de los individuos humanos vivientes, implica, ante todo, negar radicalmente toda separación entre Naturaleza y Sociedad y rechazar todo antropocentrismo. $\mathrm{O}$, si se prefiere, supone partir de la afirmación básica de que el ser humano es naturaleza ${ }^{11}$.

La materialidad del cuerpo remite indefectiblemente al enraizamiento históricomaterial que lo humano tiene respecto de la Naturaleza en general. Una perspectiva histórico-materialista - como la que propone Marx - nos lleva a reconocer que, históricamente, venimos de la Naturaleza: somos parte del proceso natural de irrupción, despliegue y complejización de la materia en el transcurso geológico de la vida en el planeta. Y que fisiológicamente, dependemos de la Naturaleza: los cuerpos humanos vivientes (naturaleza interior) tienen una relación de dependencia existencial con el conjunto de seres vivos y de factores y condiciones biosféricas de la Tierra (naturaleza exterior). La Tierra -como sistema viviente- nos excede, nos precede y nos contiene absolutamente. Nuestra vida es estructural y funcionalmente dependiente de una sistemática e ininterrumpida vinculación material con el resto de la Naturaleza en general. Por tanto, lo humano no puede ser escindido de la naturaleza; no puede ser pensado o concebido como algo exterior, ajeno o contrapuesto a la naturaleza.

En segundo término, al partir de los cuerpos, Marx coloca la cuestión de la vida - la problemática de los individuos humanos vivientes- en la base de su construcción teórica y en el centro de sus preocupaciones políticas. A diferencia del idealismo, del empirismo naturalista y del materialismo mecanicista (cada uno, en sus diferentes variantes), Marx no concibe el mundo ni como "idea" ni como "cosa", sino como vida-práctica. En Marx, lo real es lo vivo en cuanto tal: el conjunto de procesos práctico-materiales a través de los cuales acontece la vida en general; y también, en particular, la vida humana, como una expresión históricoespecífica de aquella.

Esto abre la perspectiva en dos direcciones fundamentales para una racionalidad ecológico-política. En un sentido general, una concepción histórico-materialista de

\footnotetext{
11،LLa naturaleza es el cuerpo inorgánico del hombre; es decir, la naturaleza en cuanto no es el mismo cuerpo humano. Que el hombre vive de la naturaleza quiere decir que la naturaleza es su cuerpo, con el que debe mantenerse en un proceso constante, para no morir. La afirmación de que la vida física y espiritual del hombre se halla entroncada con la naturaleza no tiene más sentido que el que la naturaleza se halla entroncada consigo misma, y que el hombre es parte de la naturaleza" (MARX, 1844)
} 
la realidad/vida implica una apertura epistémica a las nociones de complejidad y relacionalidad como atributos intrínsecos de la misma. Se destaca la importancia de las relaciones como nodo clave en la gestación, irrupción y re-producción de la vida. Ello significa eludir todo reduccionismo al respecto; es decir, la vida/mundo no pueden ser pensados como algo inerte, ni como "objeto", ni como "sujeto". La vida no está en las partes sino en las relaciones; no es una propiedad de los individuos, sino una condición, un estado y un proceso de la Naturaleza (materia/energía), así entendida como totalidad sistémica, compleja, relacional, siempre en movimiento.

En el específico sentido de la economía política, el materialismo histórico no separa las relaciones de producción del mundo de la vida; las relaciones de producción de las que primariamente parte Marx para pensar y analizar la realidad, son las relaciones de producción que están naturalmente orientadas y dirigidas a la reproducción de la vida ${ }^{12}$. Esto significa apartarse de todo productivismo y economicismo, entendiendo por tales, posturas que fragmentan y aíslan la producción de bienes económicos - tanto valores de uso como valores de cambio-, respecto de los procesos vitales y sociales en general. Para Marx, lo que interesa y lo que constituye el punto cero y el suelo positivo de la historia es "la producción material de la vida inmediata" (MARX; ENGELS, 1974, p. 19). Justamente, esto es lo que coloca en la raíz de su crítica del capitalismo: el hecho de constituir un sistema social fundado en una históricamente inédita cosificación de la vida (LÖWY, 1991); el instaurar un régimen de relaciones sociales puramente instrumental /utilitarista, y donde la cosificación (mercantilización) de la vida involucra insoslayablemente la deshumanización de lo humano.

En tercer término, al partir de la materialidad corporal de la existencia humana, para dar cuenta de la especificidad de lo humano, Marx remite a la especificidad de las relaciones que el ser humano establece con el resto de los seres vivos para procurar su subsistencia. Es ahí que plantea la cuestión del trabajo y del metabolismo entre sociedad y naturaleza como un núcleo fundamental de su pensamiento (FOSTER, 2000).

En efecto, mediante el concepto de metabolismo social ${ }^{13}$ Marx refiere a los imprescindibles y continuos intercambios energético-materiales que vinculan a los

\footnotetext{
12،“Esta concepción de la historia consiste, pues, en exponer el proceso real de producción, partiendo para ello de la producción material de la vida inmediata... (...) No se trata de buscar una categoría en cada período, como hace la concepción idealista de la historia, sino de mantenerse siempre sobre el terreno histórico real..." (MARX; ENGELS, 1974, p. 40).

${ }^{13}$ El concepto de trabajo se reconoce como una categoría fundamental dentro del marxismo; no así la categoría de metabolismo, que ha permanecido mayormente desconsiderada, o al menos entendida como algo marginal. Sin embargo, el concepto marxiano de trabajo no puede concebirse como una categoría aislada; su sentido integral se comprende dentro del marco general del proceso específicamente humano de (re)producción de la vida, lo que remite al concepto de metabolismo
} 
cuerpos humanos vivientes con el resto de los seres y elementos de la biósfera, haciendo de tal modo materialmente posible su sobrevivencia. Dichos intercambios consisten en flujos energético-materiales que circulan en dos grandes direcciones, y cuyos vectores claves son el alimento y el trabajo: de un lado, hay un flujo fundamental de agua, aire y alimento que va de la Tierra a los cuerpos/poblaciones proveyendo los nutrientes básicos de los que dependen. Del otro lado, ello supone un correlativo flujo energético que va de los de los cuerpos-poblaciones a la Tierra en forma de trabajo social. Éste, como energía inseparablemente física-psíquicaemocional, "es la condición universal para la interacción metabólica entre el hombre y la naturaleza, la perenne condición de la existencia humana impuesta por la naturaleza" (MARX, 1867).

Se comprende así, en qué medida, para Marx, el metabolismo social es la condición ecológico-política fundamental para la existencia de los individuos y las sociedades humanas. A través de las nociones de metabolismo social y de trabajo, da cuenta, por un lado, del proceso de irrupción de lo humano en la historia de la materia (hominización). La emergencia de lo humano como tal dentro del proceso geo-histórico-biológico de complejización de las formas de vida, acontece como producto el específico obrar humano (trabajo) en la procuración de su subsistencia; es por medio de su propia práctica, que el ser humano viviente va produciendo a sí mismo como un ser socio-cultural, tecnológico y político, como rasgos distintivos de la especie ${ }^{14}$.

Por otro lado, correlativamente, es esa misma práctica humana orientada a producir su vida -genéricamente llamada "trabajo"- la que da lugar al proceso histórico-geográfico de producción de la/s cultura/s. Pues, así como a través del alimento-agua-aire la naturaleza-exterior (Tierra) es literalmente in-corporada a la naturaleza-interior (cuerpo humano), del mismo modo, el trabajo humano transforma y re-crea la naturaleza exterior; a través del lenguaje, de sus recursos cognitivos y dispositivos tecnológicos, y mediante la productividad emergente de los específicos procesos de colaboración social, los colectivos humanos imprimen la humanidad de lo humano sobre la Tierra, produciendo las específicas geografías históricamente existentes, como una segunda naturaleza-exterior o naturaleza socializada (territorios - territorialidades - culturas).

En definitiva, lo humano y la historia como tal, surgen a partir del propio proceso específicamente humano de producción de la vida. En este sentido

\footnotetext{
social, clave no sólo de la antropología de Marx, sino también de su específica crítica del capitalismo (FOSTER, 2000).

${ }^{14}$ Para Marx, a través del trabajo, el hombre "pone en movimiento las fuerzas naturales que forman parte de su propio cuerpo, sus brazos, sus piernas, su cabeza y sus manos, con el fin de apropiarse de los materiales de la naturaleza de una forma adecuada a sus propias necesidades. (...) [Y] A través de este movimiento actúa sobre la naturaleza exterior y la cambia, y de este modo, cambia simultáneamente su propia naturaleza..." (MARX, 1867).
} 
ecológico integral e histórico específico, la práctica es el fundamento de la existencia humana. En cuanto tal, está intrínseca y originariamente referida a la vida; es decir, el objeto y el sentido de la práctica humana/trabajo social es la (re)producción de la vida.

Es en este marco epistémico-filosófico general, que Marx inscribe su crítica de la economía política. Para Marx, la cuestión de fondo es que el capitalismo supone una negación de la humanidad de lo humano y una contradicción de la forma naturalmente humana de (re)producción de la vida. Como sistema histórico de producción, se erige sobre la negación de la vida como finalidad de la existencia, y sobre la expropiación de las condiciones de posibilidad de realización de lo humano en cuanto tal.

Claro, el problema del capitalismo se inicia con la propiedad privada; pero ésta no es sólo ni en sí "el problema", sino todo lo que implica y desencadena; es decir, el régimen de relaciones sociales que se construye a partir de la apropiación privada lexpropiación de los medios de producción (de la vida). Privación es negación. Por eso, Marx define y concibe el proceso histórico de instauración de la propiedad como un proceso de ruptura, de falla metabólica ${ }^{15}$. Se trata de una ruptura traumática, violenta, del metabolismo bio-económico entre sociedad y naturaleza, y que altera y entra en contradicción con "las leyes naturales de la vida misma".

A partir de su instauración, todo el sistema productivo en particular, y el sistema de relaciones sociales en general, deja de estar ordenado a su fin ético y político originario. Es decir, estamos -por primera vez en la historia- ante un sistema social que se desentiende por completo de la reproducción de la vida. Un sistema que no sólo piensa lo "económico-productivo" como momento ab-soluto de la vida social $^{16}$, que lo concibe como esfera separada de los procesos energético-materiales a través de los cuales acontece la vida en general, sino que -además y por sobre todas las cosas- deja de considerarlo como medio y pasa a definirlo como fin. Este proceso se materializa social e institucionalmente en un régimen de producción que deja de estar ordenado por los valores de uso, para pasar a estructurarse en torno al valor de cambio.

Esta inversión fundamental es lo que define la naturaleza específica del capitalismo y lo que constituye su característica histórica definitoria. El modelo civilizatorio del capital instituye el excedente como valor supremo y fin último de

\footnotetext{
${ }^{15}$ Encuadrando esta fractura en el proceso de enclousures y de expropiación del campesinado, Marx señala. "El latifundio reduce la población agraria a un mínimo siempre decreciente y la sitúa frente a una creciente población industrial hacinada en las grandes ciudades. De este modo da origen a unas condiciones que provocan una fractura irreparable en el proceso independiente del metabolismo social, metabolismo que prescriben las leyes naturales de la vida misma". (MARX, 1867).

${ }^{16}$ Remitimos acá al análisis de Karl Polanyi (1989) sobre la disolución de las "ataduras" morales que el capitalismo opera respecto a la actividad económica en general y en particular a la tierra, el trabajo y el dinero.
} 
la vida social; lo instituye como principio rector, estructurador del conjunto sistémico de las relaciones sociales en general. De tal modo, subordina el sistema de reproducción de la vida al (sub)sistema de producción de mercancías y acumulación de valor abstracto.

Esa inversión supone una enajenación radical de la materialidad de la vida y del sentido de la vida. La institución de la propiedad privada implica una expropiación no sólo de los medios de subsistencia, sino ya de las condiciones de posibilidad de la realización de la vida -humana como tal. Así, el régimen de propiedad desvirtúa y corroe todo el complejo sistema de relaciones que hacen a la gestión eco-biopolítica de la (re)producción humana de la vida: afecta y desnaturaliza las relaciones con la tierra y con todos los seres no-humanos; afecta las relaciones de los seres humanos entre sí; y afecta las relaciones del ser humano con su propio trabajo y -por tanto- consigo mismo.

De tal modo entonces - como se dijo-, no es posible contraponer (ni lógica, ni histórica, ni políticamente) la explotación de la fuerza de trabajo a la explotación de la Naturaleza (exterior). El régimen de explotación/alienación de la fuerza de trabajo nace históricamente de las condiciones estructurales creadas a partir de la apropiación privativa de la tierra (es decir, de los bienes naturales vitales genéricamente entendidos como medios de subsistencia). No en vano Marx caracteriza las consecuencias de la instauración del régimen de propiedad / falla metabólica, como "martirologio de los productores": es el metabolismo del capital, antagónico al metabolismo "prescripto por las leyes naturales de la vida", el que, en su funcionamiento, sacrifica a los productores-de-la-vida, "las fuentes originarias de toda riqueza" 17 .

En esta perspectiva, por consiguiente, no se puede definir ni analizar críticamente el capitalismo como un sistema basado en la contradicción Capital vs. Trabajo como una única gran contradicción fundamental. Tampoco resulta satisfactoria la propuesta de James O'Connor de "complementar" o "ampliar" la crítica, agregando a aquella (supuesta) "primera contradicción", una "segunda contradicción" (Capital vs. Naturaleza) que sí tomaría en cuenta las consecuencias de "la apropiación y el uso económicamente autodestructivos, por parte del capital,

\footnotetext{
17،"En la agricultura, como en la manufactura, la transformación capitalista del proceso de producción aparece como martirologio de los productores; el medio de trabajo, como medio de sojuzgamiento, de explotación y empobrecimiento del obrero; la combinación social de los procesos laborales, como opresión organizada de su vitalidad, libertad e independencia individuales. La dispersión de los obreros rurales en grandes extensiones quebranta, al mismo tiempo, su capacidad de resistencia, mientras que la concentración aumenta la de los obreros urbanos. Al igual que en la industria urbana, la fuerza productiva acrecentada y la mayor movilidad del trabajo en la agricultura moderna, se obtienen devastando y extenuando la fuerza de trabajo misma. Y todo progreso en la agricultura capitalista no es sólo un progreso en el arte de esquilmar al obrero, sino a la vez en el arte de esquilmar el suelo; todo avance en el acrecentamiento de la fertilidad de éste durante un lapso dado, un avance en el agotamiento de las fuentes duraderas de esa fertilidad.” (MARX, 1867).
} 
de la fuerza de trabajo, la infraestructura y el espacio urbano, y la naturaleza externa o ambiente" (O'CONNOR, 2001, p. 212). En realidad, el régimen de relaciones sociales que instituye el capital supone una negación y una contradicción fundamental y absoluta con la vida en general y con todo sistema social de reproducción de la vida humana en particular. La devastación ecológica, hasta el umbral mismo del riesgo de (auto)extinción de la especie humana en la que nos hallamos, así como la destrucción imperialista (histórica y contemporánea) de pueblos y mundos-de-vida-otros (es decir, geoculturas no-capitalistas), pone de manifiesto que la contradicción fundamental inherente al capitalismo es la contradicción Capital vs. Vida.

\section{Revolución ecosocialista para el siglo XXI: cambio metabólico y giro agro- cultural}

"Desde el punto de vista de una formación económico-social superior, la propiedad privada del planeta en manos de individuos aislados parecerá tan absurda como la propiedad privada de un hombre en manos de otro hombre. Ni siquiera toda una sociedad, una nación o, es más, todas las naciones contemporáneas reunidas, son propietarias de la tierra. Sólo son sus poseedoras, sus usufructuarias, y deben legarla mejorada, como bonipatres familias a las generaciones venideras" (MARX, El Capital, 1867).

La sumarísima revisión de los elementos fundamentales del materialismo histórico propuesto por Marx nos parecen suficientemente claros para re-pensar la centralidad y radicalidad que ad-quiere la dimensión ecológica en su crítica de la economía política del capital, así como también para revisar con no menor radicalidad las formas y estrategias desde las cuales se procuró la construcción del socialismo en el siglo pasado (y se lo sigue pensando en el presente desde cierta izquierda "anti-neoliberal").

El ecologismo de Marx viene a señalar, así, la falla sociometabólica que introduce el capital como la raíz de la alienación humana y del mundo-de-la-vida en general. Viene a indicar que ninguna opción emancipatoria, libertaria, igualitaria, ninguna perspectiva de justicia social y/o de democracia radical se puede edificar sobre los cimientos corruptos de la cosificación/mercantilización de la vida. La disolución de la relación humana-social con la tierra es lo que está en los orígenes histórico-geográficos del capitalismo; lo que determina sus condiciones sociopolíticas e institucionales de existencia y lo que determina también sus consecuencias e implicaciones ecológicas, éticas y políticas. Esa disolución (producto histórico de la violencia expropiatoria; por tanto violencia sistémica) es la que abre paso a una senda histórica de creciente devastación de las fuentes naturales de la Vida, a la sostenida y simétrica 
desnaturalización/deshumanización de lo humano/mercantilización de los cuerpos; en definitiva, al aplastamiento del mundo-de-la-vida bajo el imperio del mundo invertido de la mercancía.

Ahora bien, la ruptura de la relación humana con la tierra (al fin y al cabo, somos una especie estrictamente agro-cultural), justamente por ser la raíz de la dominación/alienación, es también el punto neurálgico a partir del cual repensar radicalmente la tarea revolucionaria en el presente, donde lo que está en juego es algo más elemental y drástico que las opciones políticas del siglo pasado. En efecto, si a principios del siglo XX, Rosa Luxemburgo planteaba la disyuntiva histórica en términos de "socialismo o barbarie" -y ya sabemos qué opción se impuso-, en el siglo XXI - como consecuencia de tanta barbarie acumulada-, frente al desafío de construir una alternativa ecosocialista, sólo queda el abismo de la extinción definitiva de las condiciones elementales de lo humano; es decir, realmente, el fin de la historia. En el siglo XXI, la tarea de la revolución ha dejado de ser un sueño utópico y pasa a resultar un requisito de sobrevivencia. Hablando en términos del más estricto realismo, o procuramos, de verdad, acabar con el capitalismo, o el capitalismo acabará con la humanidad de lo humano, ya absolutamente.

Dicho de otra manera, no tenemos margen para seguir insistiendo en los gravosos equívocos histórico-políticos del siglo pasado; no podemos seguir pensando la revolución en términos de la misma matriz epistémico-política de la modernidad-colonial-capitalista, es decir, en términos de "crecimiento", híperurbanización, híper-industrialización, "sostenimiento en empleos", expansión del "consumo", en fin, en términos de la racionalización - tecnificación mercantilización de la naturaleza y de las relaciones sociales. No hay margen para seguir ensanchando la ya enorme brecha que distancia al ser humano de la Madre-Tierra.

Por el contrario, procurando revertir el mundo invertido del capital, inspirándonos en las lecciones de Marx, pero también en la profunda sabiduría de las alternativas vidas que nos ofrecen las gran diversidad de pueblos originarios y agro-culturas todavía no completamente destruidas por la in-civilización del capital, deberíamos poder imaginar y proyectar la revolución como un gran cambio sociometabólico.

En tal dirección, pensada en términos eco-socialistas, la idea de revolución no puede ser estrechamente definida en términos de un cambio superficial en el régimen de propiedad. Yendo a la raíz de la dominación/alienación, debería procurar un cambio integral en los modos de concepción - realización de los flujos energético-materiales entre la humanidad y la Madre Tierra. Ese cambio integral en los flujos energético-materiales, debería sustraer el fenomenal despilfarro de energías primarias y sociales desde el circuito de la alocada y ciega carrera del productivismo, la acumulación sin-fin y como fin-en-sí, para redirigirlas hacia el 
objetivo ético-político fundamental de asegurar la preservación -sustentación de la Vida, como finalidad naturalmente humana de nuestra existencia.

Justamente, el concepto de Buen Vivir, re-in-surgente hoy desde lo más profundo de las resistencias descoloniales y anti-capitalistas en los territorios ancestrales y agroculturales de Nuestra América, viene precisamente a marcar la necesidad y la viabilidad de este radical cambio civilizatorio: cambiar radical y materialmente el modo de producción-de-la-vida; es decir, cambiar el modo de concebir la vida y el sentido de la vida; cambiar el modo de organizar el proceso social de producción de la vida.

En términos epistémicos, cambiar el sociometabolismo del capital por el sociometabolismo del Buen Vivir quiere decir, básicamente, producir una profunda mudanza civilizatoria, que nos haga (re)tomar conciencia de hasta qué punto los seres humanos somos Naturaleza, vivimos de ella y con ella. Epistémicamente, ese cambio implica salirse del racionalismo y del cientificismo; y abrirse a las perspectivas -también- ya abiertas por la revolución científica de las ciencias de la complejidad (GONZALEZ CASANOVA, 2004; MALDONADO, 2011). El punto de partida las ciencias de la complejidad no es otro, en realidad, que el propio punto de partida que Marx asumió para pensar lo real:partir de la centralidad de la vida; lo cual supone dejar de pensarla como cosa, o como medio, para pensarla como misterio, como fin, y como sentido-a-ser-producido.

Como vimos, la perspectiva histórico-materialista que plantea Marx no da lugar a ningún antropocentrismo, ni a ninguna visión instrumentalista/utilitarista de la Naturaleza. La Naturaleza es la fuente de emergencia y desarrollo de la vida en general, incluida la vida humana, como expresión específica de aquella. Decir que la Tierra es un sistema vivo que nos precede, nos trasciende y nos contiene, no es ningún delirio romántico, sino que se condice con una concepción estrictamente científica del mundo.

Y esto nos lleva - pasando de lo epistémico al reino de la economía política- a la cuestión central de la propiedad. Pensada como cambio sociometabólico, la revolución ecosocialista implica no sólo un cambio en la propiedad de los medios de producción; sino un cambio en el concepto mismo de propiedad, basado en la conciencia de que no puede haber ningún tipo de "propiedad" sobre la Madre Tierra. Afirmar que la Tierra no puede ser fragmentada, ni otorgada en "propiedad" - es decir, sometida al dominio absoluto de "dueño" alguno-, es un punto de partida fundamental para un cambio verdaderamente revolucionario. La tierra no puede pertenecer a nadie en particular, ya que, en realidad, todos y cada uno de nosotros pertenecemos a la Tierra.

Esto, concretamente quiere decir que no se puede tolerar ni un paso más en la mercantilización de la naturaleza, sino que, al contrario, debemos avanzar hacia su desmercantilización. Esto significa migrar hacia un nuevo régimen de la Naturaleza como Bien Común. Revolución (eco) socialista no es "distribuir 
equitativamente" la "propiedad", ni estatalizarla; es suprimir el régimen de propiedad, sacando fuera de la órbita del mercado y del valor de cambio el agua, los bosques, las semillas, la fertilidad del suelo y la biodiversidad, los minerales y las fuentes energéticas. En fin, todos los seres, elementos y procesos de la naturaleza de los que depende la vida son demasiado importantes como para que su asignación sea confiada al mercado, libre de ataduras éticas y normativas.

Como en las llamadas "economías precapitalistas", sus modos de uso deben estar sometidas a regulaciones normativas de orden superior; en particular, la tierra y el trabajo (LUXEMBURGO, 1912; POLANYI, 1989). Pero no se trataría ya de una normatividad social naturalizada, sino de un orden ético y jurídico cuya legitimidad política repose en la democratización radical y en la adecuación ecológica, científicamente informada, de las formas de disposición y uso de los bienes.

Por lo demás, como se dijo, cambiar el régimen de propiedad, implica cambiar el régimen de relaciones sociales que se erige sobre el mismo. El régimen de naturaleza como bien Común, implica la comunalización/democratización radical de la vida social en general. En términos de economía política, esto implica desprivatizar las decisiones sobre la producción, los productos, la tecnología y los procesos productivos, y sobre todo, los criterios y patrones de consumo social.

Los procesos productivos todos (los de los objetos y los de los sujetos; los de las técnicas, las necesidades, las formas sociales de la sensibilidad y el sentido social del gusto) no pueden seguir estando bajo el comando monopólico de las corporaciones. Por tanto, un cambio en el régimen sociometabólico, implica a la par de la desmercantilización de la tierra, una correlativa desmercantilización de los cuerpos y de los deseos. Esto, por un lado, supone necesariamente un cambio en el régimen social del trabajo y en las formas sociales de la organización y gestión de la cooperación social. Dicho cambio debería estar orientado hacia la reapropiación social y personal del trabajo como medio de realización y como modo autónomo de producción de la propia vida, lo que implica superar la división entre trabajo intelectual y trabajo manual y el mundo de las híper-especializaciones. El trabajo y los procesos productivos en general, debería estar sujetos a la producción de valores de uso, democráticamente definidos y priorizados, funcionando esto no sólo como regulador del ciclo de materiales sino también de una productividad social orientada a la ampliación del tiempo libre disponible.

En tal sentido, cambiar el sociometabolismo del capital por el sociometabolismo del Buen Vivir implica viene a re-centrar la(s) (bio)economía(s) en el eje de los valores de uso. No hay salida a la alienación y a la crisis ecológica si la finalidad de la producción sigue estando bajo el dominio de la ley del valor; la (i)racionalidad de la acumulación justamente no acepta límites. En términos políticamente concretos, pensar bio-económicamente la cuestión de los límites, implica des-colonizar(-nos) los sistemas productivos, los cuerpos, los deseos, los 
imaginarios, la sensibilidad y los sentidos estéticos, éticos y filosóficos del horizonte maquínico del industrialismo, el productivismo y el consumismo.En términos materiales, la cuestión de los límites, involucra repensar radicalmente el régimen energético, salir del régimen insustentable de la energía mineral, fosilista, para avanzar en la construcción de regímenes neguentrópicos (GEORGESCUROEGEN, 1996; MARTINEZ-ALIER, 2004).

En definitiva, esto implica imaginar la la revolución, en el mismo sentido que Walter Benjamin: no como la "locomotora de la historia", sino como su "freno de emergencia". Un cambio en el sociometabolismo histórico entre la humanidad y la Madre Tierra que vaya en el sentido de reconducir los procesos productivos hacia la preservación y el cuidado de la Vida, no puede hacerse profundizando el metabolismo necro-económico del capital, su destructividad sistémica, sino deteniéndolo.

La revolución como cambio sociometabólico, implica entonces un profundo cambio civilizatorio. No se trata apenas de "redistribuir la riqueza", de aplicar políticas redistributivas, sino de operar una profunda, radical, integral transformación material y simbólica en los parámetros sociales vigentes de lo que se entiende por "riqueza". En un sentido eco-socialista, en el lenguaje del Buen Vivir, luchar por un justo reparto de la riqueza no es luchar por aumentos salariales, por "empleos dignos" (lo que, en términos estrictamente marxistas, es una contradicción en sus propios términos). Más bien, va en la dirección de exigir / realizar la restitución de la Madre Tierra como Bien Común, la institucionalización del usufructo común, socializado, equitativo y democrático de los medios de vida; la ampliación y la distribución equitativa del tiempo libre disponible; por una economía de esfuerzos y energías, orientadas al cuidado y la reproducción ampliada de la Vida.

Para ello, fundamentalmente, decisivamente, un cambio a nivel sociometabólico, implica un cambio radical en las subjetividades, las sensibilidades y las sociabilidades. Un cambio eco-socialista implica nuevos sujetos; no lo sujetos sujetados a las cadenas de la producción y el consumo fetichista. Hombres nuevos y mujeres nuevas capaces de recrear sus relaciones de comunalidad, reciprocidad, diversidad y complementariedad; capaces, en definitiva de re-apropiarse de los procesos productivos, de los medios fundamentales de la Vida y del sentido de la Vida. Buen Vivir es, en definitiva, un camino y una apuesta a producir, inventar una nueva Era en la historia de la humanidad; la Era de la Justicia y la Fraternidad como condición para la Libertad plena. Pues, como enseñó Marx:

la libertad en este terreno, sólo puede consistir en que el hombre socializado, los productores libremente asociados, regulen racionalmente su intercambio de materias con la naturaleza, lo pongan bajo su control común en vez de dejarse dominar por él 
como por un poder ciego, y lo lleven a cabo con el menor gasto posible de energías y en las condiciones más adecuadas y más dignas de su naturaleza humana (MARX, 1867).

\section{Bibliografía}

ARENDT, Hannah (2003 [1958]) La condición humana. Buenos Aires: Paidós. BAUDRILLARD, Jean (2007 [1970]) La sociedad de consumo. Sus mitos, sus estructuras. Madrid: Siglo XXI.

BAUMAN, Zygmunt (1998) Trabajo, consumismo y nuevos pobres. Barcelona: Gedisa.

(2007) Vida de consumo. Buenos Aires: Fondo de Cultura Económica.

BOLTANSKI, Luc; CHAIPELLO, Eve (2002) El nuevo espíritu del capitalismo. Madrid: Akal.

CDB (2006) Perspectiva Mundial sobre Diversidad Biológica 2. Montreal: Secretaría del Convenio sobre Diversidad Biológica, ONU.

. (2010) Perspectiva Mundial sobre Biodiversidad 3. Montreal: Convenio sobre Diversidad Biológica, ONU.

DALY, Hermann (2013) Una economía en estado estacionario. Revista Nueva Sociedad, ${ }^{\circ}$ 244, marzo-abril. Caracas: Nueva Sociedad. pp. 134-141.

ELBERS, Joerg (2011) ¿Crecimiento o cáncer? La economía en tiempos del cambio climático. Revista Letras Verdes, $\mathrm{n}^{\circ}$ 9, mayo - septiembre. Ecuador: Flacso. pp. 26-34.

ETC GROUP (2012) ¿Quién controlará la economía verde? Informe $n^{\circ} 107$. Ottawa: ETC Group

FAO. (2010) Estado de la inseguridad alimentaria en el mundo. La inseguridad alimentaria en crisis prolongadas. Roma: Organización de las Naciones Unidas para la Agricultura y la Alimentación.

FOSTER, John B. (2000) La ecología de Marx. Materialismo y naturaleza. Madrid: El Viejo Topo.

. (2007) A ecologia da destruição. Revista O Comoneiro, $\mathrm{n}^{\circ} 4$, marzo de

2007.

Disponible

en:

<http://www.ocomuneiro.com/nr04_01_JOHN_BELLAMY.html>.

. (2010) Ecologia e a transição do capitalismo para o socialismo. Revista $O$

Comoneiro, $\mathrm{n}^{\circ} 10, \quad$ marzo de 2010. Disponible en:

<http://www.ocomuneiro.com/nr10_03_bellamy.html>.

FURTADO, F.; BORBA DE SÁ, M.; ARRUDA, M.; ET AL. (2012) Economia verde: a nova cara do Capitalismo. São Paulo: Jubileu Sul Brasil.

GEORGESCU-ROEGEN, Nicholas (1977) La ley de la entropia y elproceso econômico. Madrid: Argentaria. 
GONZALEZ CASANOVA, Pablo (2004) Las nuevas ciencias y las humanidades: de la academia a la política. Barcelona: Anthropos - UNAM.

GORZ, André (2008 [1971]) Crítica de la razón productivista. Madrid: Los libros de la Catarata.

GOULDNER, Alvin (1982) The Two Marxisms. New York: Oxford University Press.

HABERMAS, Jürgen (1986 [1968]) Ciencia y técnica como 'ideología'. Madrid: Tecnos.

. (1982) Conocimiento e interés. Madrid: Taurus.

HANSEN, James (2009) Storm of My Grandchildren: The Truthabout the Coming Climate Catastrophe and Our Last Chance to Save Humanity. New York: Crown Publishers.

IFRC (2001) World Disasters Report 2001. Ginebra: International Federation of Red Cross and Red Crescent Societies (IFRC).

. (2010) World Disasters Report 2010: Focus on urban risk. Ginebra: Mc Clean, Denie (Edit.), International Federation of Red Cross and Red Crescent Societies (IFRC).

IPCC (2007) Cambio Climático 2007. Informe de Síntesis. Informe del Grupo Intergubernamental de Expertos sobre el Cambio Climático, [Equipo de redacción principal: Pachauri, R.K. y Reisinger, A.]. Ginebra: PNUMA.

Lander, Edgardo (1990) Contribución a la crítica del marxismo realmente existente. Verdad, ciencia y tecnología. Caracas: Universidad Central de Venezuela.

(1994) La ciencia y la tecnología como asuntos políticos. Límites de la democracia en la sociedad tecnológica. Caracas: Nueva Sociedad - Universidad Central de Venezuela.

(2007) Marxismo, eurocentrismo y colonialismo. En: AA.VV. La teoría marxista hoy. Problemas y perspectivas. Buenos Aires: Clacso.

LEFF, Enrique (1994) Ecología y capital. Racionalidad ambiental, democracia participativa y desarrollo sustentable. México: Siglo XXI.

LÖWY, Michel (1990) La crítica marxista de la modernidad. Revista Ecología Política, $\mathrm{n}^{\circ}$ 1, septiembre de 1991. Barcelona: Icaria. pp. 87-94.

. (2011) Ecosocialismo. La alternativa radical a la catástrofe ecológica capitalista. Buenos Aires: Herramienta ediciones.

MACHADO ARÁOZ, Horacio (2014) Capitalismo, colonialismo y crisis ecológica. Crisis de la naturaleza y naturaleza de la crisis: síntomas. Documentos de Trabajo del CIES $n^{\circ}$ 2. Córdoba: Estudios Sociológicos Editora. Disponible en: <www.estudiosociologicos.org>.

MALDONADO, Carlos E. (2011) Termodinámica y complejidad. Una introducción para las ciencias sociales y humanas. Bogotá: Ediciones Desde Abajo. 
MAGDOFF, Fred; FOSTER, John B. (2010) What Every Environmentalist Needs to Know About Capitalism. Monthly Review, vol. 61, $\mathrm{n}^{\circ} 10$.

MARCUSE, Herbert (1964) El hombre unidimensional. México: Joaquín Mortiz. (1993) La ecología y la crítica de la sociedad moderna. Revista Ecología Política, $\mathrm{n}^{\circ}$ 5, abril de 1993. Barcelona: Icaria. pp. 73-79.

MARTINEZ-ALIER, J. (2004) El ecologismo de los pobres. Conflictos ambientales y lenguajes de valoración. Barcelona: Icaria.

MARX, Karl (1844) Manuscritos económicos y filosóficos. Disponible en: <www.marxists.org>.

. (1867) El Capital. Disponible en: 〈www.marxists.org>.

. (1977 [1867]) El Capital. Tomo I. México: Siglo XXI.

(1971 [1857]) Elementos fundamentales para la crítica de la economía política (Grundrisse). Buenos Aires: Siglo XXI.

MARX, K.; ENGELS, F. (1974 [1846]) La ideología alemana. Barcelona: Ediciones Grijalbo.

MORENO, Camila (2013) Las ropas verdes del rey. La economía verde: una nueva fuente de acumulación primitiva. En: AAVV. Alternativas al Capitalismo/Colonialismo del Siglo XXI. Buenos Aires: Fundación Rosa Luxemburgo.

NAREDO, José M. (2006) Raíces económicas del deterioro ecológico y social. Más allá de los dogmas. Madrid: Siglo XXI.

O'CONNOR, James (2001) Causas naturales. Ensayos de marxismo ecológico. México: Siglo XXI.

ONU (2009) Informe de evaluación global sobre la reducción del riesgo de desastres 2009. Riesgo y pobreza en un clima cambiante. Ginebra: ONU.

PASSET, René (1996) Principios de bioeconomía. Madrid: Argentaria.

POLANYI, Karl (1989) La Gran Transformación. Crítica del liberalismo económico. Madrid: Ediciones La Piqueta.

PORTO-GONÇALVES, C. W. (2004) El desafío ambiental. México: PNUMA. RODRIGUES, Jacinto (1975) Urbanismo e Revolução. Porto: Edições Afrontamento.

SCRIBANO, Adrián (2009) Capitalismo, cuerpo, sensaciones y conocimiento: desafíos desde una Latinoamérica interrogada. En: NAVARRETE, J. M. (edit.) Sociedad, cultura y cambio en América Latina. Lima: Universidad Ricardo Palma. pp. 89-110.

(2010) Un bosquejo conceptual del estado de sujeción colonial. Boletín Onteaiken, $\mathrm{n}^{\circ} 10$. Córdoba: CIECS - CONICET y UNC.

(2012) Sociología de los cuerpos/emociones. Revista Nómadas, $\mathrm{n}^{\circ} 38$. Bogotá: Universidad Central de Bogotá. 
- (2013a) Una sociología de los cuerpos y las emociones desde Carlos Marx. En: SCRIBANO, A. (comp.) Teoría social, cuerpos y emociones. Buenos Aires: Estudios Sociológicos Editora. - (2013b) Una aproximación conceptual a la moral del disfrute. Normalización, consumo y espectáculo. Revista Brasileira de Sociologia da Emoção, v. 12, n 36, dezembro. pp. 738-750. ; DE SENNA, Angélica (2014) Consumo compensatorio: ¿uma nueva forma de construir socibialidades desde el Estado? Revista Latinoamericana de Estudios sobre Cuerpos, Emociones y Sociedad, ${ }^{\circ}$ 15, año 6, agosto-noviembre. VIVIEN, Franck-Dominique (2011) Economia e Ecologia. São Paulo: Senac.

Data de submissão: 07/08/2015.

Data de aceite: 03/10/2015. 